\title{
RANCANG BANGUN SISTEM KONTROL SUHU PADA MESIN OVEN KOPI TRAY ROTARY BERBASIS ARDUINO
}

\author{
Muhammad Vikih Hardiyansyah \\ Program Studi Teknik Mesin \\ Universitas Muria Kudus \\ Email: vikihhardiyansyah@gmail.com \\ Masruki Kabib \\ Program Studi Teknik Mesin \\ Universitas Muria Kudus \\ Email: masrukikabib@umk.ac.id \\ Akhmad Zidni Hudaya \\ Program Studi Teknik Mesin \\ Universitas Muria Kudus \\ Email: Akhmad.zidni@umk.ac.id
}

\begin{abstract}
ABSTRAK
Kopi merupakan salah satu minuman yang paling umum, termasuk minuman yang paling banyak diminum di dunia. Proses pengeringan biasanya masih menggunakan cara manual. Untuk meningkatkan efisiensi mesin oven kopi harus dilengkapi dengan sistem pengatur suhu, sehingga diharapkan proses oven dapat selesai dengan cepat dan pengurangan kadar air pada kopi dapat merata. Penelitian ini bertujuan untuk merancang dan membuat sistem kendali suhu pada mesin kopi untuk mengurangi kadar air.Metode penelitian yang digunakan adalah merancang dan menguji dari analisis kebutuhan sistem kendali, perancangan, perancangan sistem kendali suhu, perancangan perangkat keras, dan perangkat lunak. Analisis desain. Untuk menstabilkan suhu di dalam oven pada kisaran suhu $46^{\circ}-52^{\circ} \mathrm{C}$. Hasil dari penelitian pada sistem kontrol ini adalah untuk membuat sistem kontrol suhu dengan tujuan mengurangi kadar air pada biji kopi dengan cara proses oven berbasis mikrokontroler Arduino. Hasil pengujian menunjukkan rata-rata akurasi temperatur bawah $99,73 \%$ dan rata rata akurasi temperatur atas $99,64 \%$ dengan rata-rata error $0,31^{\circ} \mathrm{C}$
\end{abstract}

Kata kunci : sistem kontrol suhu, mikrokontroler arduino, sensor suhu DS18B20

\begin{abstract}
Coffee is one of the most common drinks, including the most widely drunk beverage in the world. The drying process usually still uses manual methods. To increase the efficiency of the coffee oven machine, it must be equipped with a temperature control system, so that it is hoped that the oven process can be completed quickly and the reduction in water content in the coffee can be evenly distributed. The objective of research is to design and create a temperature control system in a coffee oven machine to reduce moisture content. The research method used is to design and test the control system requirements analysis, design, design a temperature control system, design hardware and software. Design analysis. To stabilize the temperature in the oven at a temperature range of $46^{\circ}-52{ }^{\circ} \mathrm{C}$. The results of research was create a temperature control system with the aim of reducing the moisture content in the coffee beans by means of an Arduino
\end{abstract}


microcontroller. The test results show that the average temperature accuracy is below $99.73 \%$ and the average temperature accuracy is above $99.64 \%$ with an average error of $0.31{ }^{\circ} \mathrm{C}$.

Key words: temperature control system, Arduino microcontroller, DS18B20 temperature sensor.

\section{PENDAHULUAN}

Kopi merupakan komoditas perkebunan dan memiliki nilai ekonomi tinggi di perkebunan lain. Pertumbuhan produksi kopi di Indonesia masih terhambat oleh rendahnya kualitas biji kopi yang dihasilkan sehingga mempengaruhi perkembangan akhir produksi kopi. Pasalnya, proses pengeringan kopi saat ini masih mengandalkan panas matahari sebagai sumber panas utama, serta membutuhkan waktu yang relatif lama untuk mengeringkan kopi secara sempurna dan menyiapkannya untuk dikupas atau terpeleset..

Salah satu proses terakhir untuk mendapatkan biji kopi berkualitas tinggi adalah melalui proses oven. Sebelum menggunakan oven kopi, karena suhu oven tidak stabil dan pencampuran masih manual, serta kinerja masih manual, proses oven kopi manual tidak dapat menghasilkan kopi berkualitas tinggi, sehingga diperlukan pencampuran yang tidak merata selama proses roasting [1].

Perkembangan mesin oven kopi, permintaan akan teknologi juga semakin meningkat. Oleh karena itu penggunaan teknologi semakin tinggi dan tinggi terutama dengan adanya mesin-mesin maka industri membutuhkan mesin oven kopi untuk mendapatkan kopi yang berkualitas dan harga yang bagus. Mulai dari mesin oven kopi yang ada saat ini masih digunakan tanpa mesin pembuat kopi. Sistem kontrol suhu telah di kembangkan untuk proses sangrai kopi. Sistem kontrol yang di gunakan adalah fuzzy logic controller [2].

Mesin oven kopi merupakan mesin yang digunakan untuk mengurangi kelembapan pada kulit biji kopi dengan kadar air $12-13 \%$, sehingga dapat diolah lebih lanjut. Prinsip kerja mesin adalah memanaskan produk dalam oven yang berputar pada suhu tertentu untuk mendistribusikan panas secara merata. Salah satu jenis pemanas oven kopi adalah elemen pemanas listrik, dimana sistem kerjanya masih dikontrol secara manual dengan saklar atau dikontrol secara semi otomatis menggunakan timer yang dioperasikan oleh operator. Proses oven kopi menentukan rasa kopi, sehingga perlu dilakukan oleh operator yang ahli di bidangnya. Pengembangan mesin oven kopi telah di lakukan dengan memperhatikan permintaan pelanggan dan aspek ergonomi, hasil yang di capai mesin menggunakan energi listrik dengan kapasitas $2 \mathrm{~kg}$ [3].

Sistem pengendali suhu pada mesin penyangrai ini ini terdiri dari perangkatpenyusun yaitu perangkat mekanik danperangkat elektronik. Perangkat mekanik danperangkat elektronik di padukan agar mesinpenyangrai dapat bekerja secara otomatis.Perangkat mekanik terdiri dari tabungelpiji, katup gas, pengapian tungku, tabungpenyangrai, dan wadah pendingin. Tabungpeyangrai dan wadah pendingin dipadukandengan perangkat elektronik yaitu motor DC.Hal ini dilakukan agar biji kopi yang diolah,dapat diaduk secara otomatis. Untuk menciptakan suhu penyangraian yangterkendali, ditambahkan perangkat elektonikyaitu sensor suhu, mikrokontroler, dan motorservo. Sensor suhu ditempatkan pada tabungpenyangrai. Data suhu tabung penyangraiyang diamati menggunakan sensor suhukemudian diolah menggunakan mikrokontroleruntuk menghasilkan aksi kendali. Aksi kendali yang dimaksud adalah pergerakan aktuatordari sistem kendali, yaitu motor DC jenis servoyang mengatur pergerakan katup gas. Suhu pada tabung penyangrai dan pergerakan dari aktuator sistem dapat diamati melalui LCD(Liquid Crystal Display)[1].

Pembuatan progam sistem kontrol dilakukan dengan menggunakan software Arduino UNO. Bahasa pemrograman dengan menggunakan logic $\mathrm{C}++$. Proses pemrograman dilakukan pada saat mikrokontroler terhubung pada software Arduino dengan menggunakan penyambung kabel USB sebagai penghubung board Arduino dengan software Arduino. Pemrograman arduino dilakukan dengan terlebih dahulu menulis perintah program yang akan dibuat pada software Arduino dengan membuat program pada void stup program. Pemrograman yang ditulis pada 
bagian ini merupakan perintah program yang dijalan kan sekali dan penulisan program pada void loop penulisan pemrograman yang perintah programnya dilakukan berulang-ulang [4]. Sistem kontrol menggunakan arduino uno juga telah di lakukan untuk pengendalian proses penimbangan. Respon mikrokontroler ini baik dan mudah dalam pembuatan pemrograman [5]. Jenis mikro kontroller lainnya yang dapat digunakan adalah mikrokontroller ATMEGA 286. Mikrokontroler ini telah digunakan untuk pengendalian urutan proses [6]. Mikrokontroller Arduino Uno juga telah digunakan untuk sistem kontrol debit air pada pengendalian instalasi pompa [7].

Penelitian ini adalah bertujuan untuk membuat sistem kontrol suhu pada mesin oven kopi tray rotary untuk mengurangi kadar air pada biji kopi berbasis mikrokontroler arduino dan sensor suhu DS18B20.

\section{METODOLOGI PENELITIAN}

Data proses rancang bangun sistem kontrol suhu dan putaran alat prototype mesin oven kopi dapat dilihat diagram alir sebagai pada gambar 1.

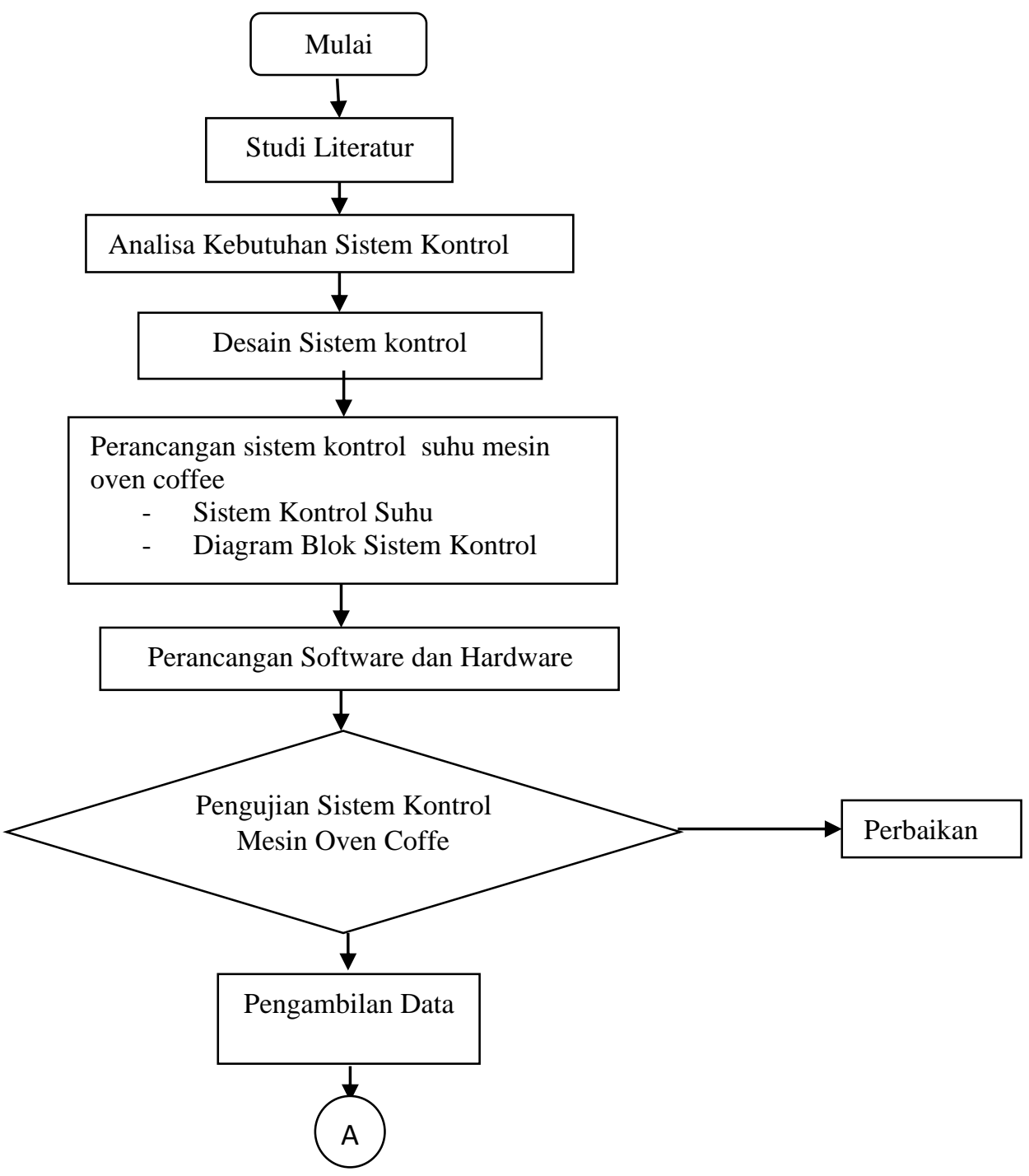




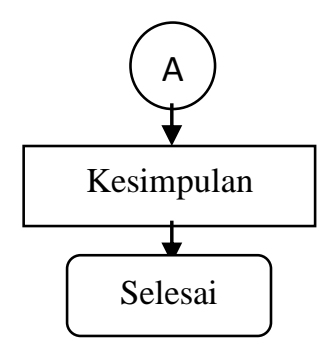

Gambar 1 Diagram alir rancang bangun sistem kontrol oven kopi

Penelitian literatur meliputi pencarian dan penelitian bahan pustaka yang berkaitan dengan segala hal yang berkaitan dengan perancangan sistem pengatur suhu oven kopi. Bahan tersebut berasal dari berbagai sumber, antara lain buku, publikasi ilmiah, dan survei mengenai komponen dan bahan standar yang beredar di pasaran. studi pustaka ini juga melakukan observasi lapangan secara langsung terhadap mesin kopi. Peneliti mengekstrak beberapa informasi dari peneliti sebelumnya, sebagai pembanding terdapat kelebihan dan kekurangan. Selain itu peneliti menggali informasi dari buku dan jurnal penelitian untuk memperoleh informasi yang ada tentang teori-teori yang berkaitan dengan judul yang digunakan untuk memperoleh landasan ilmiah..

\section{HASIL DAN PEMBAHASAN}

\subsection{Analisa kebutuhan sistem control}

Dalam rancang bangun sistem kontrol ini analisa kebutuhan sistem kontrol box oven kopi:

\section{Aspek manufaktur}

a. Konstruksi perancangan sistem kontrol pembuatan agar komponen tertata rapi.

b. Kebutuhan komponen :

1). Arduino, 2). Kabel, 3).Sensor suhu DS18B20, 4).LCD, 5).Relay, 6). Pematik, 7).Driver Motor, 8). Push Buttom, 10). Power Suply, 11). Selenoid

2. Aspek Teknik

a. Sistem kontrol dapat mendeteksi temperatur suhu.

b. Menggunakan temperatur $46^{\circ}-52^{\circ} \mathrm{C}$ untuk proses oven kopi.

c. Pengendalian sensor suhu untuk mengatur temperatur pada mesin oven.

3. Aspek Sistem Kontrol

a. Dibutuhkan sistem kontrol lup tertutup..

b. Dibutuhkan sensor suhu dengan akurasi tinggi.

c. Dibutuhkan mikrokontroler yang dapat mengendalikan suhu di mesin oven kopi tray rotary.

4. Aspek Keselamatan Kerja

Perancangan catu daya pada sistem kontrol diletakkan pada box yang telah disesuaikan dengan desain mesin, sehingga keselamatan terjamin.

\subsection{Desain Mesin}

Pada gambar 2 menunjukkan desain mesin oven kopi dengan arduino. Mesin ini dilengkapi dengan, $L C D$, dan Sensor suhu. 


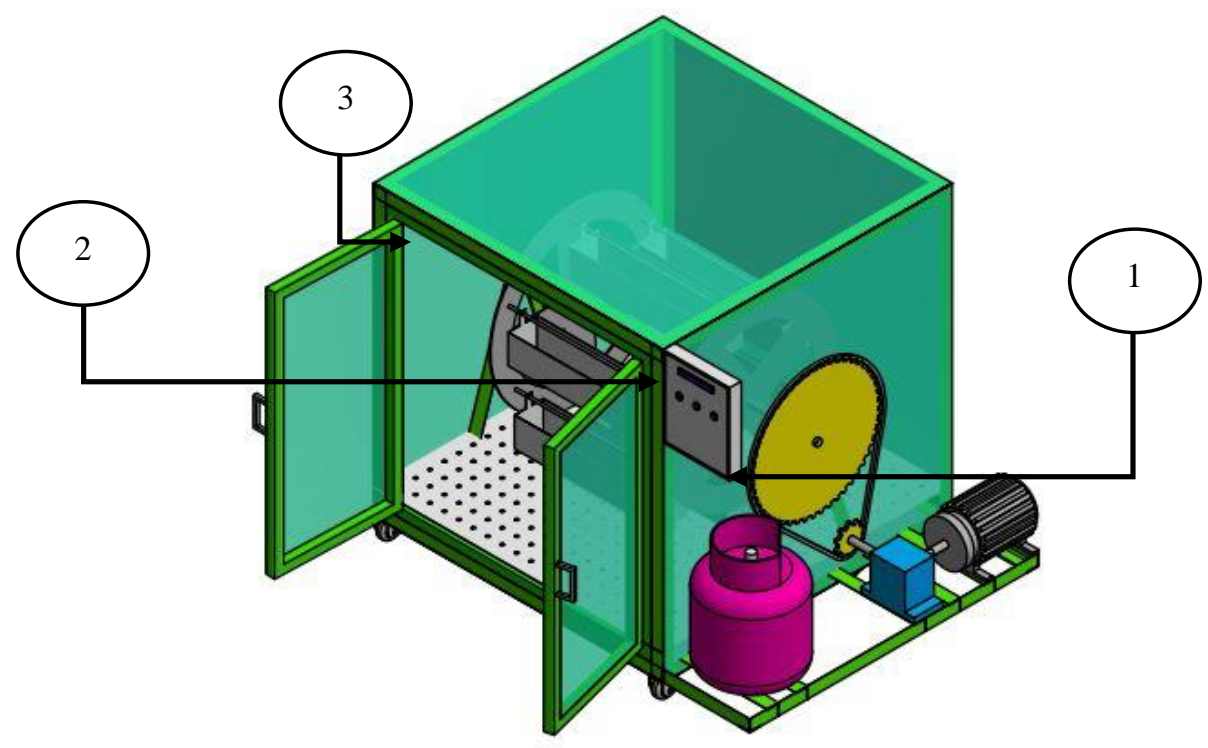

Gambar 2. Desain Mesin oven kopi tipe tray rotary..

Mesin ini dilengkapi dengan komponen berikut: pertama (1) panel kontrol, kedua (2) LCD, ketiga (3) sensor suhu

Gambar 3 merupakan diagram blok desain sistem kontrol pada mesin oven kopi dengan menggunakan mikrokontroller arduino Uno.

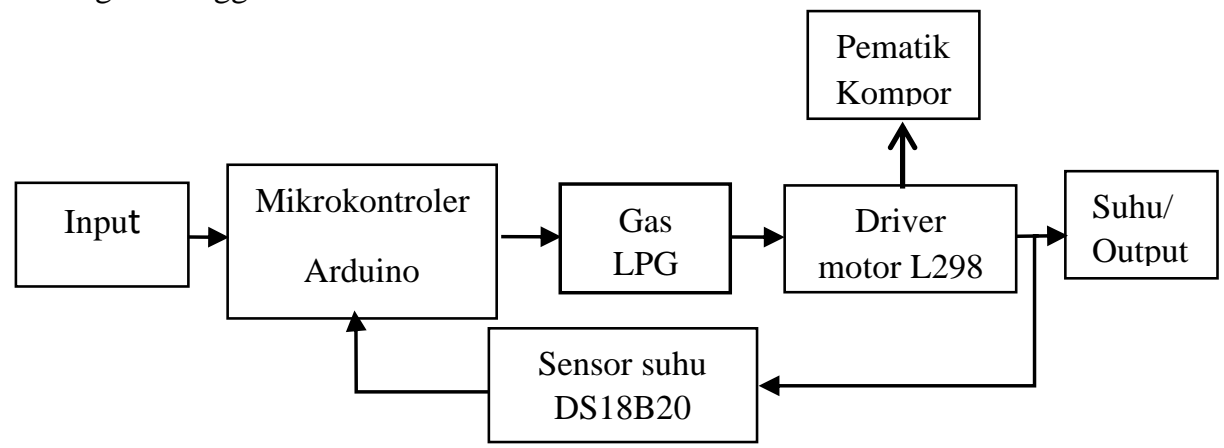

Gambar 3. Diagram blok desain sistem kontrol

Diagram pada Gambar 3 adalah sistem kontrol oven kopi. Input pertama berupa setting temperaataur dari sistem memasuki Arduino, kemudian memerintahkan untuk membuka katup gas LPG, dan kemudian memerintahkan ke pemantik api melalui penggerak motor DC untuk menyalakan api. Apabila sensor suhu telah mendeteksi temperatur telah terpenuhi maka mikrokontroler Arduino memerintahkan untuk menutup gas LPG sehingga api mati. 


\subsection{Perhitungan panas}

Untuk menentukan kebutuhan kalor pemanasan dilakukan perhitungan temperatur pemanasan. Perpindahan panas secara konduksi dihitung berdasarkan persamaan 1:

$$
\mathrm{Q}_{\mathrm{x}}=-\frac{\mathrm{K} \cdot \mathrm{A}}{\mathrm{L}} \cdot\left(\mathrm{T}_{2}-\mathrm{T}_{1}\right)
$$

$$
\begin{aligned}
& \text { Dimana : } \\
& A=500 \mathrm{~mm}^{2} \\
& L=2 \mathrm{~mm} \\
& T_{1}=46^{\circ} \mathrm{C} \\
& T_{2}=52^{\circ} \mathrm{C} \\
& K=19 \frac{\mathrm{W}}{\mathrm{m}^{2}} \cdot k \\
& T_{S 1}=50^{\circ} \mathrm{C} \\
& h=0,193 \\
& T_{02}=26
\end{aligned}
$$

Perpindahan panas secara konveksi di hitung berdasarkan persamaan 2 :

$$
-Q=h A\left(T_{S}-T_{00}\right)
$$

Hambatan perpindahan panas konveksi dihitung berdasarkan persamaan 3:

$$
-\mathrm{R}_{\mathrm{konveksi}}=\frac{\Delta \mathrm{T}}{2}=\frac{1}{\mathrm{hA}}
$$

Maka laju perpindahan panas tiap hambatan dihitung berdasarkan persamaan 4 :

$$
-Q_{X}=\frac{\left(T_{S 1}-T_{1}\right)}{\frac{1}{h o 1 A}}=\frac{\left.T_{2}-T_{1}\right)}{\frac{L}{K A}}=\frac{T_{2}-T_{02}}{\frac{1}{h o A}}
$$

Hasil perpindahan kalor Konveksi dihitung berdasarkan persamaan 5:

$$
-Q_{X}=\frac{T_{s 1}-T_{02}}{R_{\text {total }}}=\frac{\Delta T}{R_{\text {total }}}
$$

\subsection{Pembuatan Hardware}

Pada Gambar 4 menunjukkan desain instalasi Hardware, untuk mngetahui perancangan pada sistem pembuatan perangkat keras. Pembuatan hardware pada sistem kontrol pengatur temperatur menggunakan sensor suhu DS18B20, LCD, Driver Motor Rellay Push Buttom menggunakan Arduino. 


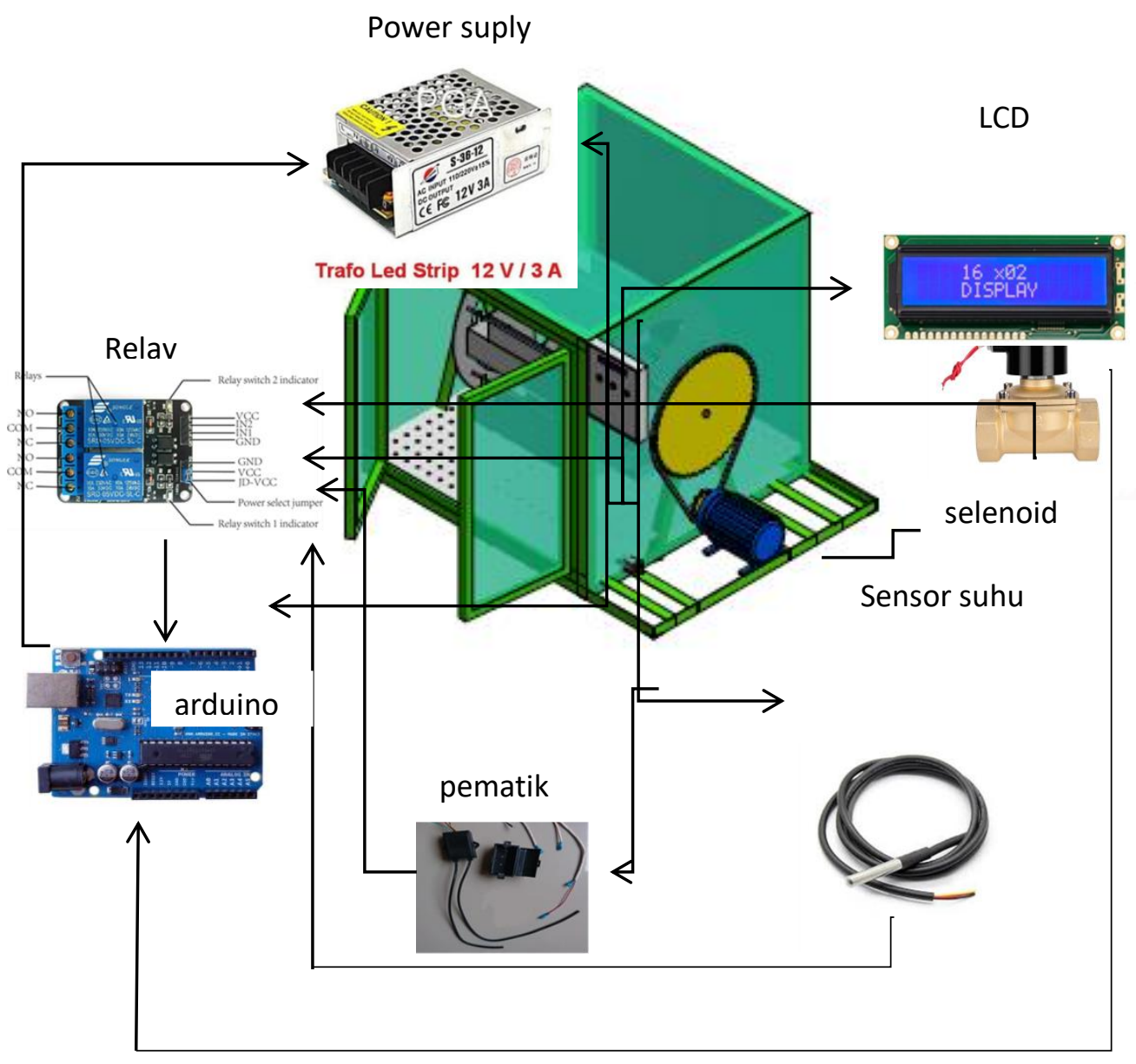

Gambar 4 Desain Instalasi Hardware

\subsection{Pembuatan Pemrograman Sistem kontrol}

Pada gambar 5 menunjukan pemrograman sistem kontrol yang sudah diaplikasikan ke hardware mesin oven kopi tipe try rotary . 


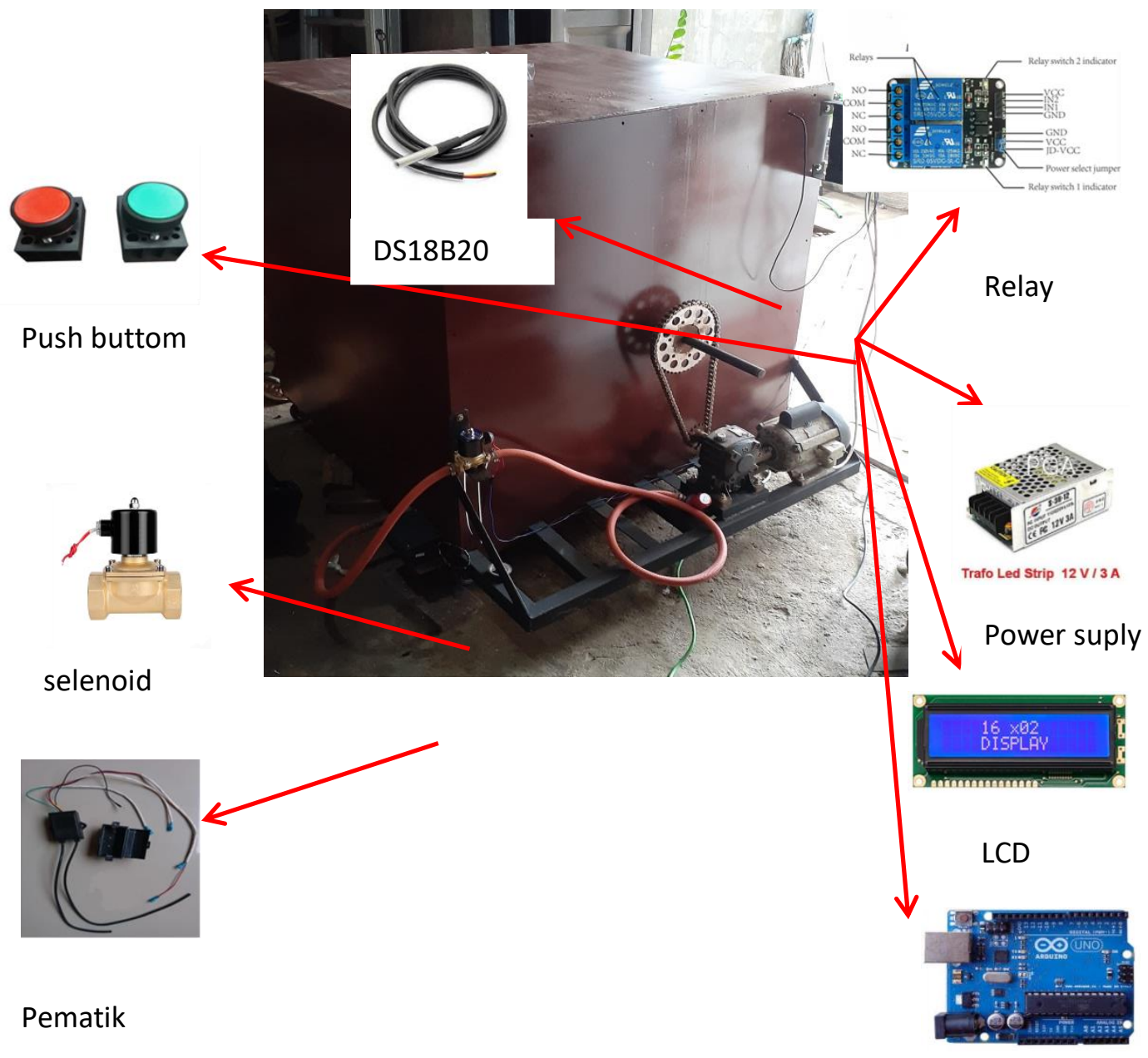

Gambar 5 Gambar hasil perancangaan hardware

\section{Arduino}

Penjelasan gambar hasil hardware :

1. Arduino berada dalam bok.

2. LCD berada dalam bok.

3. Power suply berada dalam bok.

4. Relay berada dalam bok.

5. Push buttom berada dalam bok.

6. Seleoid berada pada kanan belakang mesin.

7. Pematik berada pada belakang bawah mesin.

8. Sensor suhu berada pada kanan atas mesin.

Proses pengujian bahan dimasukkan ke dalam ruang oven kemudian menyalakan sistem kontrol yang telah di atur setting temperaturnya pada $46^{\circ} \mathrm{C}$ sebagai temperatur bawah dan $52^{\circ} \mathrm{C}$ sebagai temperatur atas, kemudian ketika sudah menyala katup selenoid akan membuka dan mengalirkan gas ke kompor dengan secara secara otomatis pematik akan merespon untuk menyalakan kompor dan ketika kompor menyala sensor suhu akan mendeteksi panas pada ruangan dan ketika suhu mencapai batas atas selenoid akan menutup aliran gas 
yang ke kompor sehingga api akan meredup dan bila temperatur berapa pada temperatur bawah seleoid akan membuka kembali aliran gas ke kompor sehingga api menyala kembali. dan dilakukan 4 kali pengujian sehingga didapatkan hasil sebagaimana tabel 1.

Tabel 1 pengujian sistem kontrol temperatur

\begin{tabular}{|c|c|c|c|c|c|c|c|c|c|}
\hline No & 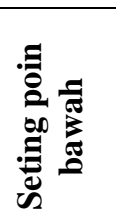 & 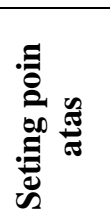 & 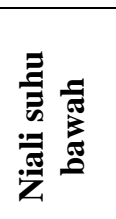 & 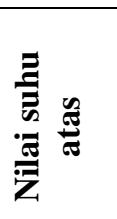 & 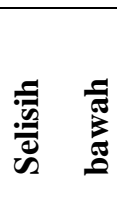 & 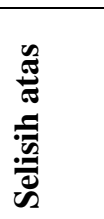 & 离 & 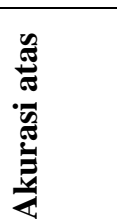 & $\ddot{\grave{0}}$ \\
\hline 1. & $46^{\circ} \mathrm{C}$ & $52^{\circ} \mathrm{C}$ & 46.25 & 52.50 & 0,25 & 0,50 & 99,46 & 99,04 & 0,75 \\
\hline 2. & $46^{\circ} \mathrm{C}$ & $52^{\circ} \mathrm{C}$ & 46.00 & 52.00 & O & 0 & 100 & 100 & 0 \\
\hline 3. & $46^{\circ} \mathrm{C}$ & $52^{\circ} \mathrm{C}$ & 46.00 & 52.25 & 0 & 0,25 & 100 & 99,51 & 0,25 \\
\hline 4. & $46^{\circ} \mathrm{C}$ & $52^{\circ} \mathrm{C}$ & 46.25 & 52.00 & 0,25 & 0 & 99,46 & 100 & 0,25 \\
\hline
\end{tabular}

Pengujian sistem kontrol dilakukan untuk menguji keberhasilan implementasi sistem control temperatur yang sudah dibuat dan sudah sesui dengan yang diinginkan sistem kontrol suhu. Pada pengujian sistem kontrol suhu disetting batas bawah dengan temperatur $46^{\circ} \mathrm{C}$ dan batas atas disetting $52^{\circ} \mathrm{C}$ dengan empat kali percobaan. sehingga mendapatkan hasil rata-rata akurasi temperatur bawah $99,73 \%$ dan rata rata akurasi temperatur atas $99,64 \%$ dengan rata-rata error $0,31^{0} \mathrm{C}$.

\section{KESIMPULAN}

Pengaturan suhu terhadap temperatur di kontrol menggunakan arduino, dengan suhu di atas batas yang sudah di tentukan $\left(52^{\circ} \mathrm{C}\right)$ selenoid akan menutup mematikan api dan jika suhu di bawah batas yang ditentukan $\left(46^{\circ} \mathrm{C}\right)$ seleoid akan mememperaturbuka gas dan pematik akan hidup untuk menyalakan api. Hasil pengujian sistem kontrol suhu menggunakan sensor suhu DS18B20 menghasilkan respon sesuai dengan yang diharapkan dan mampu diaplikasikan pada sistem kontrol suhu karena error yang didapatkan rata-rata sebesar $0,31^{\circ} \mathrm{C}$ dan masih dalam toleransi. Pembacaan dan pengendalian sistem kontrol menunjukkan respon yang baik,

\section{DAFTAR PUSTAKA}

[1] Anilatul Bahroin, A. Prijo Budijono, 2015, Rancang Bangun Sistem Kontrol Suhu Dan Putaran Pada Mesin Penyangrai Kopi Semi Otomatis, Jurnal Rekayasa Mesin, Volume 2Nomor 3, pp. 35-39

[2] Satrio Budhi Utomo, Moh Agung, P.N. Sumardi, 2015, Perancangan Sistem Pengaturan Suhu Pada Mesin Sangrai Kopi Berbasis Logika Fuzzy, Jurnal Rekayasa Mesin Vol.6, No.2, pp: $107-110$

[3] Putra Zakaria Purnama, Nelly Budiharti2, Thomas Priyasmanu, 2020, Rancang Bangun Mesin Oven Kopi Dengan Prinsip QFD Dan Ergonomi, Jurnal Valtech (Jurnal Mahasiswa Teknik Industri)

Vol. 3 No. 2 , pp. 25-31.

[4] Kushartanto, P, Kabib M., Winarso R., 2019 'Sistem kontrol gerak dan perhitungan produk pada mesin pres dan pemotong kantong plastik, Jurnal crankshaft, volume 2, No 1, pp. 57 66. 
[5] Irwanto, B., Kabib, M. and Winarso, R., 2019, Rancang Bangun Sistem Kontrol Penimbangan Tembakau Dengan Mikrokontroller Arduino Uno, Jurnal Crankshaft, Volume 2, No. 1, pp. 27-32. doi: 10.24176/crankshaft.v2i2.3837.

[6] Huda S., Kabib M., Winarso R., 2017, Desain Automatic Line Plastic Packing of Cake Berbasis Mikrokontroler ATMEGA 328, Seminar SNATIF ke 3, Fakultas Teknik UMK, pp. 577-584.

[7] Saputra E, Kabib M., Nugraha B.S., 2019, Rancang Bangun Sistem Kontrol Debit Air Pada Pompa Paralel Berbasis Arduino, Jurnal crankshaft, Volume 2 No. 1, pp. 73 - 80. 